\title{
ANALISIS VISUAL WARNA PADA GAME POST APOCALYPTIC (STUDI GAME THE LAST OF US, METRO EXODUS, DAN HORIZON ZERO DAWN)
}

\author{
Daniel Kurniawan Salamoon ${ }^{1}$, Cindy Muljosumarto ${ }^{2}$ \\ 1,2 Fakultas Seni dan Desain, Program Studi Desain Komunikasi Visual, Universitas Kristen Petra \\ daniel.kurniawan@petra.ac.id ${ }^{1}$, cindy.mul@petra.ac.id ${ }^{2}$
}

\begin{abstract}
Abstrak
Video game sebagai bentuk media visual di era modern memiliki peranan dalam masyarakat sebagai salah satu bentuk hiburan yang bersifat interaktif. Video game terus berkembang dalam tata visual sebagai bentuk evolusi dari teknologi video game tersebut. Evolusi dalam video game membuat genre dalam video game juga mengalami perkembangan. Salah satu genre yang menjadi tren adalah genre post apocalyptic. Penelitian ini mencoba melihat narasi yang hendak disampaikan lewat tata visual beberapa video game dengan genre post apocalyptic. Metode yang dilakukan adalah dengan mengumpulkan data screen capture dari beberapa judul video game dengan rating yang baik. Dari metode ini, teori yang digunakan untuk melakukan analisa adalah teori semiotika khususnya yang berkaitan dengan tata visual pada video game khususnya elemen warna yang menjadi kunci genre ini dengan menggunakan software Image. Setelah itu data dianalisis lebih lanjut dengan metode AEIOU (Action, Environment, Interaction, Object, User). Studi ini memberi gambaran bagaimana tata visual yang menjadi ciri khas genre game post apocalyptic dan nilai estetis yang bisa dipelajari dari genre tersebut. Pada akhirnya studi ini dapat menjadi pondasi dalam melakukan riset warna khususnya dalam pengembangan sebuah video game
\end{abstract}

Kata kunci : desain game, post apocalyptic, video game, warna

\begin{abstract}
Video games as a form of visual media in the modern era has a role play in society as one of interactive entertainment form. Video games continue to grow in visual elements as evolution forms from video game technology itself. The evolution of video games also makes the genre of video games experience development. This research attempts to observe the narrative is to be conveyed through the visual elements of several video games with the Post-apocalyptic genre. The method used was to collect screen capture data from several video game titles with good ratings. The theory that used to conduct the analysis is a semiotic theory relate to visual elements, especially the colors element that is the key to this genre. The theory that used to conduct the analysis is a semiotic theory relate to visual elements of the video game, especially the colors element that is the key to this genre. The theory that used to conduct the analysis is a semiotic theory relate to visual elements of the video game, especially the colors element that is the key to this genre using image software. Afterward, data analyzed subsequently with AEIOU's (Action, Environment, Interaction, Object, User) method. This study gives a description of how the visual elements become a characteristic of the Post-apocalyptic genre and the aesthetic value that can be learned from the genre. So eventually these studies can be the foundation in conducting color research especially in the development of a video game.
\end{abstract}

Keywords: color, game design, post apocalyptic, video game 


\section{PENDAHULUAN}

Perkembangan kehidupan manusia di era teknologi semakin ditandai dengan adanya kebutuhan untuk selalu terhubung dengan media-media informasi. kebutuhan akan hiburan dan komunikasi, teknologi digital mempengaruhi perilaku masyarakat baik individu maupun lembaga dan komunitas yang mau tidak mau harus beradaptasi dengan perkembangan jaman. Meskipun teknologi bersifat netral dan sangat dipengaruhi individu pemakainya, tetapi sebagai artefak, teknologi justru menentukan arah peradaban dan kebudayaan (Straubhaar \& LaRose, 2008). Perkembangan media yang terus menerus, membuat masyarakat kini menjadi masyarakat yang termediasi (Ritzer, 2012). Citra audio dan visual yang ditampilkan oleh media-media masa kini menjadi daya tarik sumber informasi sekaligus hiburan di tengah masyarakat.

Sebagai bagian dari perkembangan teknologi khususnya dalam ranah hiburan, video games selama ini menjadi stigma di masyarakat terkait dengan kebiasaan buruk pemainnya. Hal ini biasanya dilihat dari permainan yang menawarkan violence atau kekerasan hingga mengumbar seksualitas. Ada juga beberapa akademisi yang memberikan analisis terkait efek kecanduan yang ditimbulkan akibat dari permainan digital. Dalam jurnal Cyberpsychology and Behaviour, menuliskan bahwa potensi kecanduan dari permainan digital sangat besar dan bisa menjadi "penyakit" bagi pemainnya. Meski demikian, perkembangan ini tidak bisa terhindarkan. Makin majunya teknologi berimbas pada makin berkembangnya permainan digital baik dalam segi gameplay maupun tampilan grafis.

Dalam industri video game, perkembangan teknologi ini terlihat dari makin variatifnya gameplay dan tampilan grafis yang ditampilkan. Efek lanjutan dari hal ini berdampak pada tata cerita dan tata visual yang menjadi inti dari sebuah judul video game. Dalam beberapa tahun ini, video games dengan genre cerita post apocalyptic cukup menjadi perhatian serta meraup keuntungan yang cukup besar. Beberapa contoh diantaranya seperti: The Last of Us yang dikembangkan oleh Naughty Dog yang terjual 1,3 juta salinan pada minggu pertama peluncuran dan mencapai 17 juta salinan pada 2018 (Tassi, 2013).

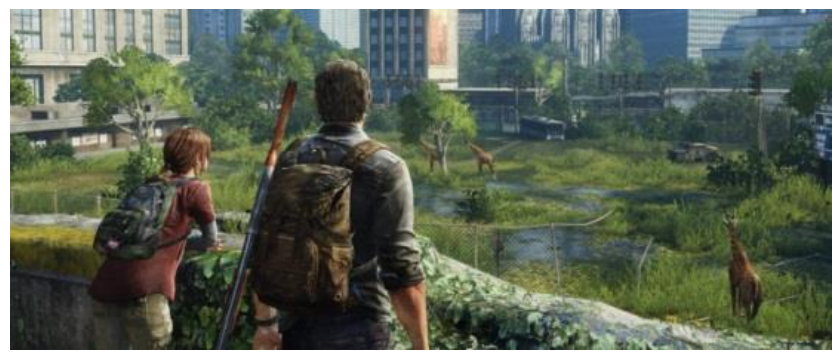

Gambar 1. Footage The Last of Us

[Sumber : www.hardcoregamer.com]

Kemudian ada Fallout 4 yang dikembangkan oleh Bethesda yang terjual 1,2 juta salinan dalam 24 jam peluncuran (Davidson, 2015). Selain itu yang menjadi sensasi yaitu Horizon Zero Dawn yang dikembangkan oleh Guerrilla Games yang penjualannya mencapai 10 juta salinan pada tahun pertama peluncuran (Parfitt, 2017). Melanjutkan daftar video 
game dengan genre cerita post apocalyptic, pengembang 4A Games meluncurkan judul Metro Exodus (kelanjutan seri Metro) pada Februari 2019. Metro Exodus mendapat nominasi dari majalah Develop untuk kategori Best Visual Arts dan Game of The Year. (Blake, 2019).
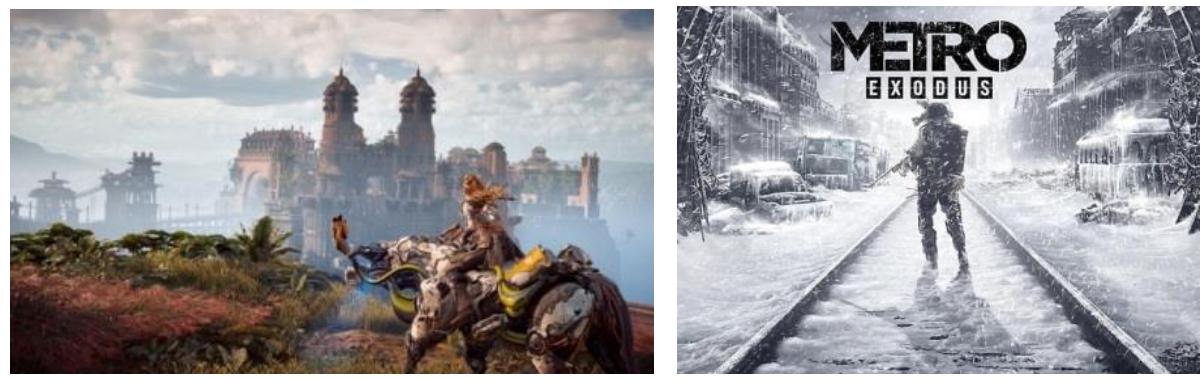

Gambar 2. (kiri) Footage game Horizon Zero Dawn dan (kanan) cover game Metro Exodus [Sumber : https://www.ebgames.com.au,_www.gamivo.com]

Hasil penjualan dari beberapa judul video game tersebut menunjukkan bahwa penerimaan dari para pemain cukup besar terhadap genre post apocalyptic. Dalam ulasan singkatnya, Michael Klappenbach mendeskripsikan genre post apocalyptic sebagai genre yang luas dimana mencakup cerita terkait masa depan baik yang akan datang maupun jauh ke depan atau menceritakan tentang alternatif sejarah yang terjadi (Klappencbah, 2019). Selain itu dari G2A memberikan deskripsi sebagai genre dimana cerita berpusat pada sebuah kejadian setelah terjadi masa kekacauan atau bencana luar biasa yang bersifat global. Bencana tersebut dapat berupa asteoroid yang menabrak bumi, perang nuklir atau zombie. Apapun penyebabnya, genre post apocalyptic berpusat pada sebuah kondisi dimana segala sesuatu yang umum ditemui sudah berakhir dan pemain dihadapkan pada kondisi atau realitas yang berbeda dengan kewajaran yang biasa dikenal pada dunia nyata. (Poole, 2017)

Adanya penjabaran dari genre terkait post apocalyptic pada dunia video game serta penerimaan dari para pemain, membuat genre ini menjadi menarik untuk dapat dipelajari. Studi ini mencoba membahas bagaimana genre post apocalyptic ini menyajikan dirinya kepada para pemain video games khususnya dalam tata visual yang ditampilkan. Untuk penelitian ini, maka kajian akan difokuskan pada tiga judul video game yaitu The Last of Us, Metro dan Horizon Zero Dawn. Analisis akan dilakukan untuk membaca elemen visual yang ditampilkan sehingga bisa didapatkan pola tertentu yang secara visual menjadi gambaran besar dalam penciptaan genre dalam video game, khususnya pada genre post apocalyptic.

\subsection{Permainan Digital dan Konsumsi Visual}

Dalam bukunya, Yasraf Amir Piliang menulis sebuah kondisi masyarakat posrealitas. Dimana penanda utamanya adalah realitas mereka tidak lagi dalam sebuah realitas, tetapi lebih jauh merupakan realitas yang dianggap sebagai bukan realitas tetapi menjadi realitas karena persetujuan dari anggota masyarakat dan penerimaan dalam wacana konsumsi. Konsumsi tanda lahir dari posrealitas dimana masyarakat melakukan tindakan konsumsi karena sebuah pemaknaan terhadap tanda. Bukan lagi sekedar kebutuhan tetapi pada pencarian makna dalam konsep posrealitas. (Baudillard, 2004). 
Dalam perkembangan era modern, tanda menjadi sebuah nilai jual. Bukan sekedar benda atau bentuk fisik, tetapi ada permainan baru dalam komoditas saat ini adalah komoditas tanda. Permainan digital adalah sebuah dunia tanda yang luas. Pemain memaknai dirinya untuk ambil bagian dalam permainan tersebut adalah dengan menciptakan tanda, misalkan membuat avatar tertentu atau nama alias yang dianggap mewakili keberadaaan dirinya. Karakter yang dimainkan akan dilengkapi dengan baju, senjata dan perlengkapan yang menciptakan sebuah representasi bahwa dirinya ada di dalam situ. Tanda juga banyak muncul dalam cerita dalam desain lingkungan serta aktivitas dalam permainan digital.

Permainan pada umumnya memiliki sifat addictive terlebih pada permainan digital dimana terbungkus dalam petualangan, cerita hingga desain karakter yang menarik. (Ng \& Wiemer-Hastings, 2005). Secara budaya, pada dasarnya manusia memiliki hasrat untuk bermain. (Huizinga, 2014). Hasrat natural tersebut kemudian dimunculkan dalam bentuk sebuah permainan (culture). Keberadaan permainan digital saat ini tidak bisa dilepaskan dari kondisi natural untuk bermain pada diri manusia. Dalam sebuah judul permainan, maka hal yang diutamakan adalah pengalaman bermain. Pengalaman yang dibangun merupakan sebuah kesadaran abstrak yang dibangun pada diri pemain dalam interaksi dengan permainan tersebut. Terkait pengalaman terhadap permainan digital ini, Brian Sutton-Smith seperti dikutip oleh Salen dan Zimmerman, menyajikan lima elemen yang membangun pengalaman bermain; 1) Visual Scanning : persepsi visual yang dibangun oleh tata visual pada layar permainan secara langsung. 2) Auditory discriminations : mendengarkan sinyal dan event suara tertentu. 3) Motor responses: aksi fisik yang diambil pemain melalui papan kontrol permainan. 4) Concentration : fokus pada permainan. 5) Perceptual patterns of learning : proses pemain memahami struktur permainan secara utuh.

Dalam proses bermain, kelima elemen ini saling berkolaborasi dalam membangun pengalaman bermain khususnya terkait permainan digital. (Salen \& Zimmerman, 2004). Lebih lanjut terkait permainan digital, cerita, penokohan hingga interaktivitas dalam gameplay menjadi sebuah kebutuhan untuk dikonsumsi. Dalam tulisannya, Baudillard (2004) mengungkapkan mengenai hiperrealitas yaitu taman hiburan Disneyland. Dalam konteks Baudillard, Disneyland merupakan representasi dari khayalan dan fantasi yang tidak ada. Disneyland melambangkan sebuah dunia imajiner dimana pengunjung disana seolah merasa di dunia yang berbeda dengan pertunjukan, permainan dan aktivitasaktivitas di sana.

\subsection{Estetika Dalam Video Game}

Video Game merupakan sebuah "dunia" tanda yang luas. Dunia tanda yang dijual kepada masyarakat dengan janji berupa kesenangan, horor dan hal-hal yang tidak dapat ditemui dalam realitas. Permainan digital memberikan sebuah aktvitas aktivasi tanda bagi para pemainnya. Para pemain akan dapat melakukan banyak hal yang tidak dapat dilakukan di dunia nyata dan mendapatkan reward atas tindakan mereka. Dalam Simulacra, Baudillard menjelaskan bahwa realitas bukanlah realitas dalam masyarakat 
modern yang sudah sangat akrab dengan keberadaan media di sekitarnya. Realitas yang dialami merupakan bentukan dari media di sekitarnya yang mereka lihat dan gunakan sehari-hari. (Ritzer, 2012)

Video game merupakan media kompleks yang melibatkan indera dan rasa manusia dalam menggunakannya. Indera visual untuk mengamati dan memahami proses sebuah gameplay dari game yang dimainkan serta indera pendengaran untuk merasakan suasana yang ditawarkan lewat tata suara dan tata musik yang ada di dalam game tersebut. Elemen-elemen tersebut merupakan elemen yang membangun pengalaman bermain bagi pemain. Video game sebagai bentuk utuh dari tata desain yang rumit, menekankan unsur pengalaman bermain. Pengaturan terhadap tata letak, desain karakter serta pengalaman bermain dalam video game membuat Aaron Smuts berargumen bahwa video game memiliki unsur seni yang dalam hal ini memberikan makna estetis. (Smuts, 2005). Lebih lanjut, Smuts memaparkan bahwa dari teknik pengaturan cahaya, tata letak, desain karakter yang menyerupai kondisi asli merupakan penerapan teknik seperti pembuatan film yang di dalamnya terdapat banyak unsur penerapan teori-teori seni yang mengedepankan pengalaman estetis.

Dalam keilmuan semiotika yang mempelajari tentang tanda, maka video game dengan berbagai macam unsurnya tersebut merupakan kumpulan tanda yang akan memberikan makna bagi penggunanya. Tanda-tanda ini yang akan menciptakan pengalaman bermain. Mengutip dari Kirkpatrick (2011), video game merupakan objek plastik yang bisa dimainkan dengan leluasa untuk memberikan kesan dan makna dari pengalaman bermain tersebut.

Semiotika sendiri adalah ilmu yang mempelajari tentang tanda. Semiotika berasal dari kata Yunani semeion, yang berarti tanda. Semiotika, sebagaimana dijelaskan oleh Fedinand de Saussure adalah ilmu yang mempelajari peran tanda (sign) sebagai bagian dari kehidupan sosial. Semiotika adalah ilmu yang mempelajari struktur, jenis, tipologi, serta relasi-relasi tanda dalam penggunaannya di dalam masyarakat. Tradisi semiotik terdiri atas sekumpulan teori tentang bagaimana tanda-tanda merepresentasikan benda, ide, keadaan, situasi, perasaan dan kondisi di luar tanda-tanda itu sendiri. (Littlejohn, 2009). Kehidupan manusia tidak pernah lepas dari pemaknaan sehari-hari terhadap tanda. Tanda tidak bisa berdiri sendiri, tanda menjadi bermakna ketika dimaknai oleh orang lain, sehingga pemaknaan inilah yang menjadi kunci dalam sebuah pemahaman terhadap representasi tanda. Dalam kenyataannya, manusia sebagai pengguna tanda berperan pula dalam proses terbentuknya realitas. Kita sebagai pihak yang memproduksi dan mengkonsumsi tanda punya kuasa untuk ikut membangun realitas lewat tanda. (Chandler, 2007)

\subsection{Warna dalam Game}

Warna adalah sebuah kondisi ketika bentuk atau benda mendapat cahaya. Tanpa cahaya, maka tidak akan muncul warna. Warna merupakan gelombang yang diterima indra penglihatan. Warna dapat didefinisikan secara fisik merupakan panjang gelombang elektromagnetik. Selain itu, warna juga dapat didefinisikan secara subjektif 
dalam bentuk harmonisasi warna tertentu. (Sanyoto, 2010). Dalam proses desain, warna memberikan makna dan tujuan bagi suatu objek tertentu. Pemberian warna pada suatu objek dapat menguatakan karakter dari objek atau benda tersebut. Proses pemberian warna pada desain juga untuk menarik perhatian dari orang yang melihat. Warna merupakan aspek penting yang mudah diingat khususnya untuk hal-hal baru yang dilihat oleh manusia. (Batagoda, 2017) . Kekuatan warna tersebut menjadi fungsi penting khususnya dalam game. Warna bisa menjadi elemen untuk memberikan pengalaman tertentu karena warna menciptakan rasa terhadap hasil desain yang dibuat.

\section{METODE PENELITIAN}

Penelitian kualitatif ini menggunakan pendekatan deskriptif kualitatif menggunakan metode studi kritis dengan image based research, yakni meneliti dan mengungkapkan visual image sebagai dasar penelitian. Dalam proses interpretasi, peneliti akan melakukan proses dialektikanya dengan teks sebagai obyek. Adapun langkah-langkah penelitian yang akan dilakukan adalah sebagai berikut:

1. Game The Last of Us, Metro, dan Horizon Zero Dawn sebagai objek penelitian akan didokumentasikan dan diamati secara seksama.

2. Mengamati dan memilih adegan dari Game The Last of Us, Metro dan Horizon Zero Dawn untuk dianalisis menggunakan pendekatan metodologi visual, khususnya pada area site of image itself untuk memperoleh tanda-tanda yang diartikulasikan dalam setiap tampilan tokohnya khususnya dalam konteks narasi warna dan Post apocalyptic. Peneliti bertindak untuk melakukan interpretasi, pemaknaan dan pemahaman terhadap objek visual yang diamati.

3. Penelitian ini menggunakan sudut pandang dari gambar itu sendiri (the site of the image it self), hal ini sangat berhubungan dengan subjek yang aktif (tunggal dan bukan sebagai khalayak) dalam mengintepretasi visual image.

\subsection{Teknik Pengumpulan Data}

Secara umum langkah penelitian melalui pengamatan/obeservasi terhadap objek yang diteliti, sebagai berikut yaitu 1) Dokumentasi dan observasi mendalam. Pendokumentasian aktivitas game The Last of Us, Metro dan Horizon Zero Dawn menggunakan aplikasi capture video dengan setting gambar beresolusi tinggi, agar kualitas gambar tetap baik saat tampilan gambar diperbesar, guna memudahkan proses analisis. Observasi mendalam berarti mengamati secara seksama, meliputi kegiatan pemusatan perhatian objek penelitian dengan menggunakan seluruh alat indera. 2) Kepustakaan atau studi literatur, merupakan teknik pengumpulan data yang berupa buku-buku, ensiklopedia budaya, jurnal ilmiah, majalah, situs-situs internet, artikel dan sebagainya yang berhubungan dengan topik penulisan, yakni video game, studi tentang warna dan hiperrealitas.

\subsection{Teknik Analisis Data}

Setelah data berhasil dikumpulkan, maka langkah selanjutnya adalah melakukan analisis terhadap data tersebut. Analisis data merupakan suatu usaha untuk mengkaji dan mengolah data yang sudah ada sehingga diperoleh suatu simpulan yang bermanfaat sesuai dengan tujuan. Pendekatan yang dilakukan dalam mengkaji kode visual pada 
game The Last of Us, Metro dan Horizon Zero Dawn adalah dengan metode AEIOU. Metode AEIUO merupakan metode analisis visual berdasar lima kategori yaitu Activities, Environment, Interactions, Objects dan User.

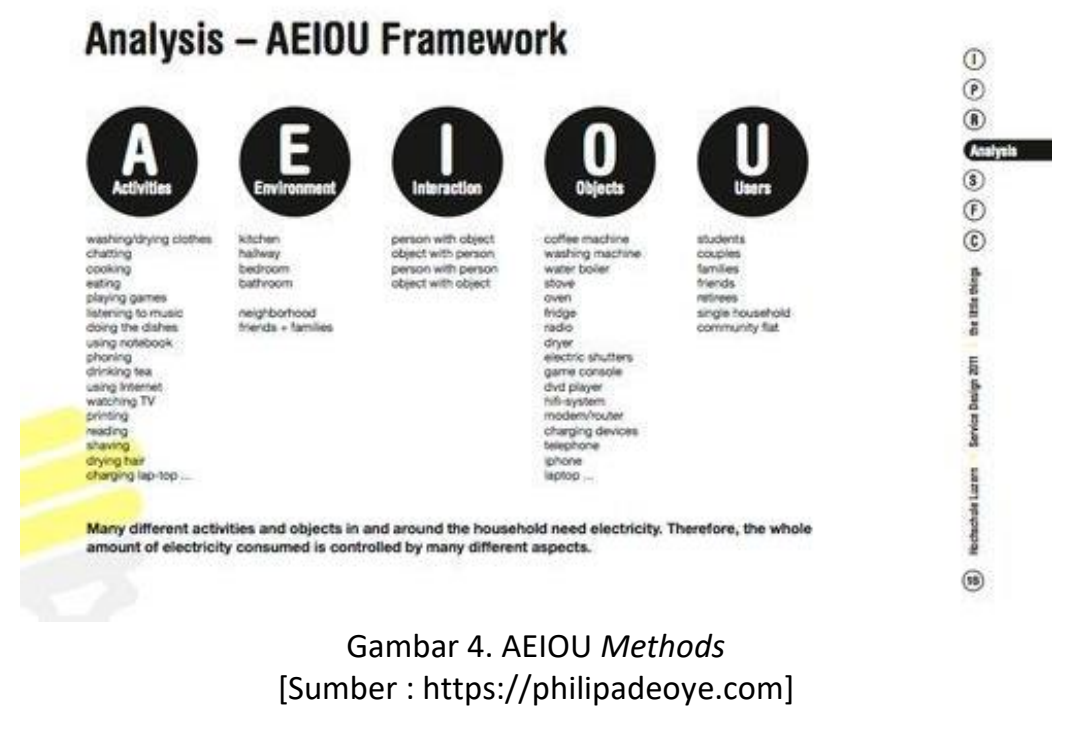

Metode ini digunakan untuk menerjemahkan data-data visual yang telah didapat untuk kemudian dilakukan triangulasi dalam menggali makna yang disampaikan data visual tersebut. Analisis yang dilakukan adalah untuk mencari hubungan antar elemen pada data visual yang didapat sehingga bisa menemukan suatu konstruksi yang dibangun lewat narasi visual pada game yang menjadi objek penelitian.

\section{PEMBAHASAN}

\subsection{Tinjauan Cerita Metro Exodus}

Metro Exodus diposisikan sebagai seri sekuel Metro: Last Light. Seperti judul yang digunakan, Exodus berfokus tidak lagi pada terowongan kereta bawah tanah Moscow yang menjadi basis dunia untuk Metro 2033 dan Metro : Last Light. Setelah apa yang terjadi di seri sebelumnya, karakter utama dari seri Metro yaitu Artyom menjadi sangat terobsesi untuk membuktikan pada penduduk Moscow yang tinggal di Metro (area kereta bawah tanah) bahwa mereka bukan satu-satunya yang selamat dari kiamat kecil yang terjadi. Bahwa ada komunitas di luar sana yang masih hidup, tumbuh, dan berkembang.

Dalam misi ekspedisinya bersama dengan sang istri - Anna, Artyom tiba-tiba menemukan sebuah kereta api yang berjalan aktif melintasi rel. Bersama dengannya adalah para tawanan yang mengaku bahwa mereka semua datang dari luar Moscow. Pertempuran besar melawan kelompok penawan ternyata membuka fakta bahwa satusatunya alasan Moscow begitu "sunyi" dari interfensi sinyal luar bukan karena tidak adanya lagi kehidupan di luar sana, tetapi karena pelacak sinyal yang pada akhirnya berhasil dihancurkan oleh Artyom. Bersama dengannya, mereka juga berhasil mengamankan sang kereta api yang mereka beri nama "Aurora". Cerita berfokus pada bagaimana Artyom dan kelompoknya berpetualang di dunia luar yang masih berkembang setelah terjadinya kiamat akibat nuklir tersebut. (Santoso, 2019) 


\subsection{Tinjauan Cerita The Last Of Us}

Cerita pada game The Last of Us dimulai dengan wabah mutan jamur Cordyceps merusak Amerika Serikat, mengubah manusia sebagai inangnya menjadi monster kanibal yang dikenal sebagai infected (terinfeksi). Di pinggiran kota Austin, Joel menyelamatkan diri dari kekacauan itu bersama adiknya, Tommy, dan putrinya, Sarah. Saat mereka melarikan diri, Sarah ditembak oleh seorang tentara dan meninggal dalam pelukan Joel. Dalam dua puluh tahun berikutnya, sebagian besar peradaban hancur oleh infeksi tersebut. Para penyintas tinggal di zona karantina yang diawasi ketat, permukiman independen, dan kelompok-kelompok nomaden. Joel bertemu dengan pemimpin Fireflies, Marlene, meminta Joel menyelundupkan seorang gadis remaja, Ellie, kepada Fireflies yang bersembunyi di luar zona karantina. Joel, Tess, dan Ellie menyelinap keluar di malam hari, tetapi setelah bertemu dengan petugas patroli, mereka mengetahui bahwa Ellie terinfeksi. Infeksi penuh biasanya terjadi di bawah dua hari, tetapi Ellie mengklaim dia telah terinfeksi tiga minggu yang lalu dan bahwa kekebalannya dapat mengarah kepada penyembuhan. Petualangan dimulai dengan cerita seputar perjalanan Joel dan Ellie untuk mencapai markas Fireflies dengan harapan kekebalan Ellie bisa menjadi obat untuk wabah yang ada.

Pada musim semi, Joel dan Ellie tiba di Salt Lake City dan ditangkap oleh petugas patroli Firefly. Di rumah sakit, Marlene memberitahu Joel bahwa Ellie sedang dipersiapkan untuk operasi: dengan harapan menghasilkan vaksin untuk infeksi tersebut, Fireflies harus membuang bagian otak Ellie yang terinfeksi, yang akan membunuhnya. Tidak mau membiarkan Ellie meninggal, Joel bertempur dalam perjalanan ke ruang operasi dan membawa Ellie yang tak sadarkan diri ke garasi parkir, di mana ia berhadapan dengan Marlene yang kemudian ia bunuh untuk mencegah Fireflies mengejar mereka. Saat berkendara keluar dari kota, Joel berbohong pada Ellie; ia mengklaim bahwa Fireflies telah menemukan banyak orang lain yang kebal, tetapi mereka tidak dapat membuat obat, dan mereka telah berhenti berusaha. (Campbell, 2018)

\subsection{Tinjauan Cerita Horizon Zero Dawn}

Cerita bermula ketika Rost melakukan ritual pemberian nama, kepada Aloy yang masih dalam keadaan Bayi. Ritual ini adalah budaya yang disakralkan oleh suku Nora. Suku Nora, adalah suku yang menganut kebudayaan Matriaki (kebalikan dari Patriaki) yaitu sistem kebudayaan, yang menganggap wanita memiliki derajat yang lebih tinggi dibandingkan dengan pria. Suku Nora memiliki pemimpin yang disebut "Matriarch." Singkat cerita Aloy ditempatkan sebagai outcast atau orang buangan, berdasarkan kenyataan bahwa ia tak memiliki ibu dan dipelihara oleh Rost. Rost adalah sosok yang dilabeli sebagai orang buangan (outcast) oleh sukunya sendiri. Rost tak boleh berbicara dan berinteraksi dengan anggota suku lain, serta tak boleh tinggal di antara komunitas sesama anggota suku. (Newton, 2017)

Petualangan Aloy membawa pemain untuk mencari tahu apa yang terjadi pada game Horizon Zero Dawn dengan menjelajah dan menyelesaikan berbagai macam misi. Yang unik adalah di dunia Horizon Zero Dawn, pemain akan berhadapan dengan makhlukmakhluk mesin yang berwujud seperti binatang. Kata "Zero Dawn" sendiri mengacu 
pada Project Zero Dawn. Petualangan ini nantinya juga menjelaskan atas alasan apa dunia dipenuhi oleh mesin mesin yang menyerupai binatang, dan menggambarkan simbol mahluk prasejarah dinosaurus. (Horizon Zero Dawn, 2017)

\subsection{Tinjauan Analisis Data Spektrum Warna}

Tabel 1.Tabel analisis spektrum warna

[Sumber: Dokumen Penulis]

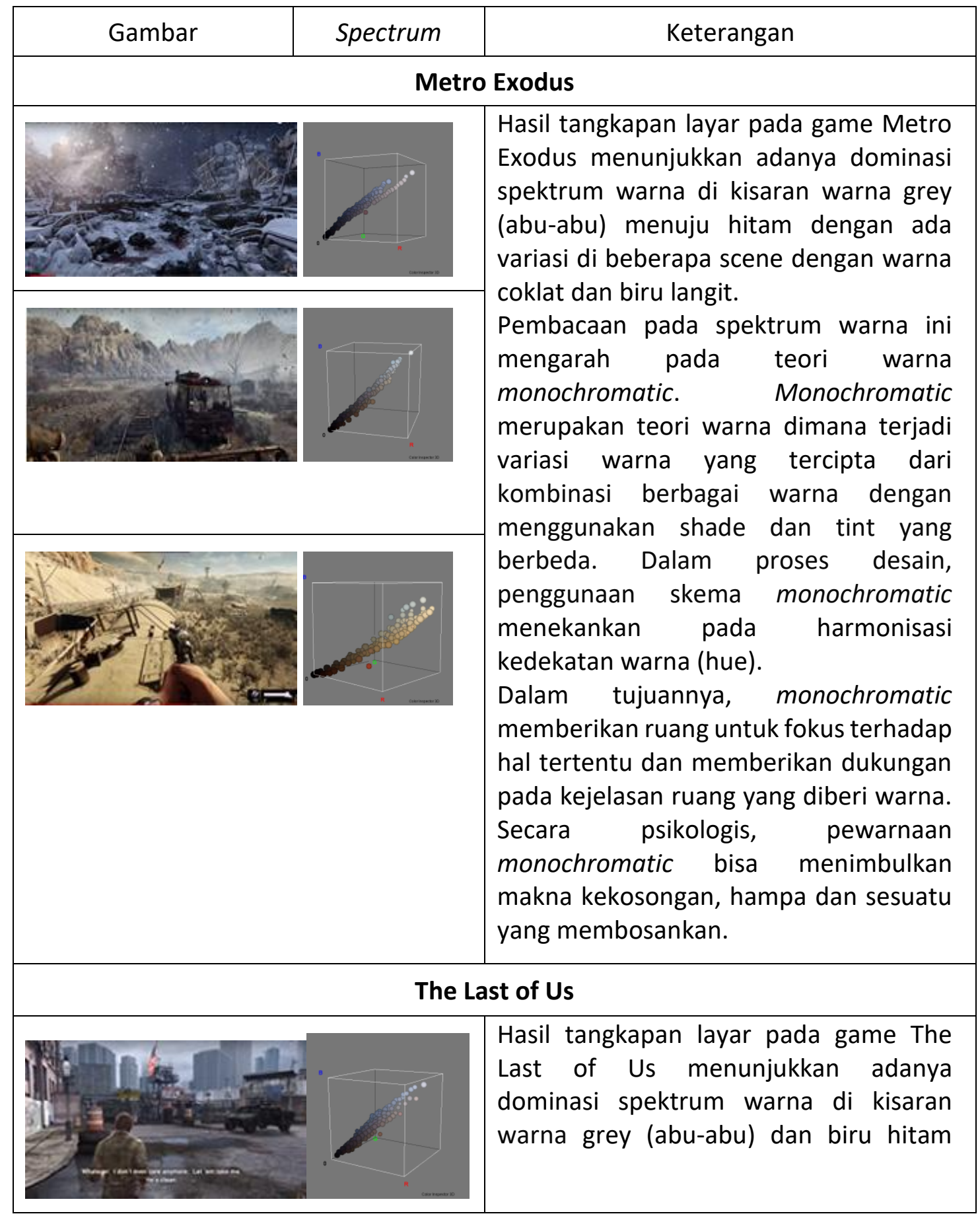




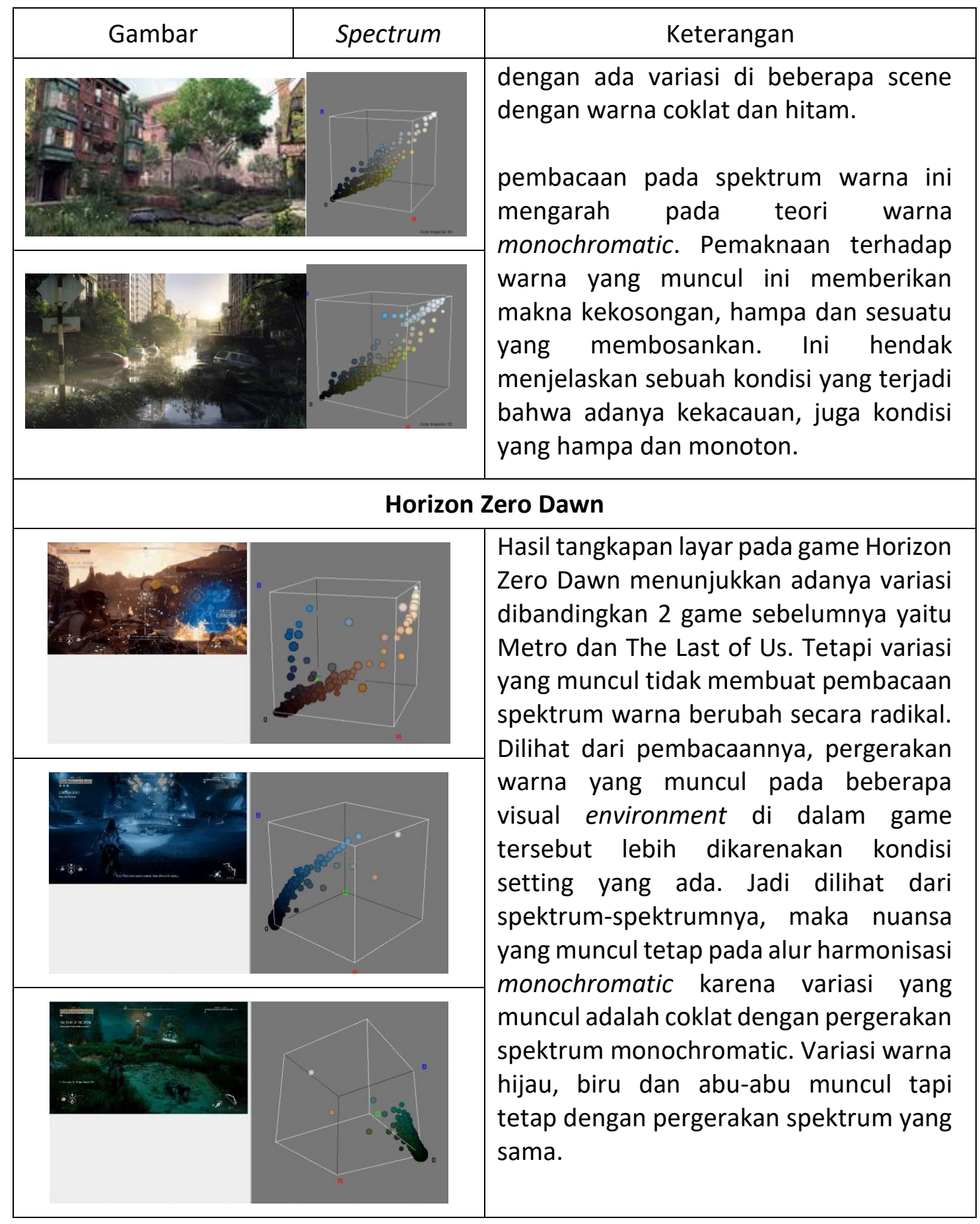

\subsection{Tinjauan Analisis Data Metode AEIOU}

Dari data yang sudah diambil lewat pengecekan spektrum warna, peneliti melanjutakan analisis data dengan metode AIEOU. Metode ini digunakan untuk dapat memilah visualisasi yang tampil pada game untuk kemudian dibandingkan dengan data pada spektrum warna sehingga bisa didapatkan makna terkait visualisasi yang nampak. 
Tabel 2. Analisis AIEOU Metro Exodus

[Sumber: Dokumen Penulis]

\begin{tabular}{|c|c|c|c|c|}
\hline Activities & Environment & Interactive & Object & User \\
\hline $\begin{array}{l}\text { - Menjelajah } \\
\text { - Bertarung } \\
\text { - Mengumpul- } \\
\text { kan material }\end{array}$ & $\begin{array}{l}\text { - Salju } \\
\text { - Padang pasir } \\
\text { - Area bawah } \\
\text { tanah (subway) } \\
\text { - Cerah } \\
\text { - Bersalju } \\
\text { - Reruntuhan } \\
\text { gedung } \\
\text { - Rongsokan } \\
\text { kendaraan } \\
\text { - Karat }\end{array}$ & $\begin{array}{l}\text { - Bersembunyi } \\
\text { - Menembak } \\
\text { musuh dengan } \\
\text { senjata api } \\
\text { - Mengisi peluru } \\
\text { - Menyembuh- } \\
\text { kan diri } \\
\text { - Berlari } \\
\text { - Menjelajah } \\
\text { - Mengumpul- } \\
\text { kan material }\end{array}$ & $\begin{array}{l}\text { - Zombie } \\
\text { - Monster } \\
\text { - Senjata api } \\
\text { - Peluru } \\
\text { - Koin } \\
\text { - Obor/korek } \\
\text { api } \\
\text { - Peta }\end{array}$ & $\begin{array}{c}\text { - Pemain } \\
\text { game }\end{array}$ \\
\hline
\end{tabular}

Tabel 3. Analisis AIEOU The Last of Us

[Sumber: Dokumen Penulis]

\begin{tabular}{|l|l|l|l|l|}
\hline \multicolumn{1}{|c|}{ Activities } & \multicolumn{1}{|c|}{ Environment } & \multicolumn{1}{|c|}{ Interactive } & \multicolumn{1}{c|}{ Object } & User \\
\hline - Menjelajah & - Perkotaan & - Bersembunyi & - Zombie & - Pemain \\
- Bertarung & - Taman kota & - Menembak & - Senjata api & game \\
- Mengumpul- & - Area bawah & - Memanah & - Pisau & \\
kan material & tanah (subway) & - Mengisi peluru & - Panah & \\
& - Pemukiman & - Menyembuh- & - Ransel & \\
& - Cerah & kan & - Peluru & \\
& - Reruntuhan & - Berlari & - Koin & \\
& - Rongsokan & - Menjelajah & - Suku & \\
& kendaraan & - Mengumpul- & cadang & \\
& - Karat & kan material & & \\
& & - Reparasi & & \\
\hline
\end{tabular}

Tabel 4. Analisis AIEOU Horizon Zero Dawn

[Sumber: Dokumen Penulis]

\begin{tabular}{|l|l|l|l|l|}
\hline \multicolumn{1}{|c|}{ Activities } & \multicolumn{1}{|c|}{ Environment } & Interactive & Object & User \\
\hline - Menjelajah & - Hutan & - Memanah & - Robot & - Pemain \\
- Bertarung & - Padang rumput & - Menyembuh- & - Hewan & game \\
- Mengumpul- & luas & kan & - Panah & \\
kan material & - Pedesaan & - Berlari & - Tombak & \\
& & - Menjelajah & & \\
& & - Mengumpul- & & \\
& & kan material & & \\
& & - Membuat & & \\
& & peralatan & & \\
& &
\end{tabular}




\subsection{Nuansa Warna dan Pengalaman Bermain}

Video game merupakan sebuah media yang unik dalam interaksinya dengan pemain. Seiring dengan perkembangan teknologi, maka video game kini menawarkan banyak hal kepada pemain. Cerita yang makin kompleks, pilihan terhadap desain karakter dan peralatan bahkan cerita yang dibangun bisa terjadi dari pilihan pemain ketika memainkan sebuah game tertentu. Video game mencoba menciptakan interaksi sehingga pemain tidak lagi sekedar menyelesaikan game tertentu tetapi terlibat dalam segala aspek untuk membuat pengalaman bermain terasa lebih menyenangkan.

Untuk membuat pemain terlibat, maka game harus di desain supaya pemain merasa bahwa "dirinya" terlibat dalam cerita yang dibangun oleh game tersebut. Dari analisis terhadap game dengan genre Post apocalyptic, pemain perlu dihadapkan pada kondisi yang terjadi setelah "kiamat". Game harus mampu menampilkan narasi visual dari elemen-elemen desainnya sehingga ada ikatan antara pemain dengan game.

Pada game Horizon Zero Dawn, Metro Exodus maupun The Last Of Us pemain terlibat dalam sebuah narasi yang menjadi bagian dari gameplay yang harus dimainkan. Bahkan setiap misi yang harus dilakukan oleh pemain berasal dari interaksi dari protagonis yang dimainkan oleh pemain dengan tokoh-tokoh NPC (karakter yang tidak dapat dimainkan) yang ikut membentuk alur narasi. Karena game ini sangat menonjolkan narasi dalam membentuk permainannya, maka pemahaman pemain dalam setiap adegan yang dilakukan sangat diperlukan. Hal ini tentunya tidak lepas dari grafis serta warna yang digunakan untuk mendukung narasi tersebut. Warna-warna tersebut ditata sedemikian rupa untuk dapat menggambarkan suasana dan mendukung cerita dari setiap adegan.

Harmonisasi warna menjadi jembatan untuk narasi visual yang muncul karena dalam desain, warna merupakan elemen penting dalam membentuk visual. Dalam dasar teori warna, warna merupakan pengalaman indra penglihatan yang merupakan hasil dari pantulan cahaya ketika menimpa benda tertentu. (Sanyoto, 2010:12). Susunan warna tertentu akan memberikan pengalaman indra penglihatan tertentu, dimana warna akan memberikan informasi terhadap suatu pengalaman kepada otak manusia. Dari hasil analisis data menunjukkan bahwa pada suatu tema game, memunculkan harmonisasi warna tertentu. Hal ini dapat membantu pemain mendapat pengalaman bermain sesuai dengan cerita dan gameplay yang ditawarkan sebuah game.

\subsection{Pemaknaan Game Post apocalyptic dengan Warna}

Berdasarkan studi warna yang telah dilakukan, didapati bahwa dari ketiga game yang menjadi objek penelitian, terdapat kemiripan dalam penggunaan teori warna. Meski berbeda tingkat penggunaan warnanya, tetapi hasil dari spektrum warna menunjukkan bahwa ketiga judul game (Metro Exodus, The Last of Us dan Horizon Zero Dawn) menggunakan harmonisasi warna monochromatic sebagai dominasi dalam tata visualnya. Harmonisasi warna monochromatic secara umum menunjukkan kesan yang monoton, seimbang dan berkesan membosankan. Hal ini dikarenakan variasi warna yang tercipta merupakan hasil dari penggunaan tint dan shade saja pada suatu nilai warna tertentu. 
Dari studi ketiga game yang menjadi objek penelitian, genre Post apocalyptic yang diusung berdasarkan sebuah kondisi yang sama yaitu pemain diminta untuk menyelesaikan cerita dari game tersebut dengan sebuah kondisi bahwa karakter utama yang dimainkan berada pada dunia yang bergerak setelah terjadinya suatu bencana besar yang menghancurkan peradaban manusia secara masif. Ketiga game yang menjadi objek memang menceritakan bencana yang berbeda, tetapi alur pergerakan cerita dalam game sama yaitu bagaimana pemain dapat bertahan pada situasi tersebut dan menyelesaikan misi-misi yang ada dengan segala keterbatasan baik peralatan maupun senjata.

Gameplay dan cerita yang membawa pemain pada kondisi terbatas itu sangat sejalan dengan tata visual khususnya dari hasil terkait tata visual warna pada ketiga game tersebut. Makna harmonisasi monochromatic yang terkesan datar, monoton dan membosankan memberikan kesan kuat terhadap dunia yang dihadapi oleh pemain yaitu dunia yang kacau, sepi dan serba terbatas. Sangat berbeda dengan game seperti Rayman atau Little Big Planet yang penuh warna dan terkesan ceria. Penggunaan harmonisasi warna tersebut sangat mendukung cerita yang ditawarkan yaitu cerita yang bersifat fantasi tetapi mengedepankan petualangan yang menegangkan. Hal ini dapat dilihat dari berbagai scene yang terkesan suram, gelap dan tidak terawat atau banyak reruntuhan. Harmonisasi warna monochromatic ternyata merupakan pilihan yang tepat untuk menggambarkan kondisi tersebut.

\section{KESIMPULAN}

Dalam perkembangan video game saat ini, bukan hanya sekedar pamer judul atau desain karakter yang menarik. Perkembangan ini terjadi karena dukungan teknologi sehingga sebuah game bisa menjadi lebih kompleks secara cerita dan gameplay. Makin mudahnya akses informasi, juga membuat pemain menjadi lebih selektif dalam memilih game. Proses riset dan desain sebuah game bisa menjadi lama demi menghasilkan game yang sempurna. Dalam interaksinya dengan pemain, game di desain sedemikian rupa untuk dapat memberikan pengalaman bermain yang optimal kepada pemainnya.

Dalam narasi genre Post apocalyptic, pemain dihadapkan pada kondisi pasca "kiamat" di bumi. Sifat cerita jelas merupakan fiksi yang belum tentu terjadi atau secara realitas tidak mungkin terjadi. Tetapi kondisi yang tidak pernah dirasakan dan ditemui oleh pemain inilah yang menjadi sisi menarik sebuah game. Tawaran untuk menjelajah sebuah dunia virtual yang tidak ada, untuk terlibat pada cerita, merasakan apa yang ditampilkan oleh visual dari game tersebut. Dalam proses penerjemahan informasi yang kompleks ini, perlu adanya jembatan antara narasi visual dengan pemaknaan dari si pemain. Dari hasil penelitian ini, salah satu elemen visual yang memegang peranan penting adalah warna. Warna adalah hal nyata yang dilihat setiap hari oleh manusia. Bentuk suatu benda menjadi jelas karena adanya warna. Warna tertentu akan memiliki fungsi dan makna tertentu juga.

Dari hasil penelitian ini, warna memegang peranan penting untuk menceritakan narasi kekacauan, kehampaan, kerusakan dan suramnya sebuah wacana pada cerita dengan 
tema Post apocalyptic. Harmonisasi warna yang dipilih, mampu menunjukkan makna terkait hal-hal yang berhubungan dengan tema Post apocalyptic. Pemilihan warna yang tepat pada sebuah narasi visual, mampu menghadirkan pengalaman visual yang sesuai juga sehingga pengalaman bermain yang ditawarkan dapat dirasakan dengan optimal.

\section{DAFTAR PUSTAKA}

Batagoda, M. (2017). Color, psychology and design. Retrieved from https://uxplanet.org Baudillard, J. (2004). Masyarakat Konsumsi. Bantul: Kreasi Wacana.

Blake, V. (2019). Shortlist for Develop:Star Awards 2019 revealed. Retrieved from https://www.mcvuk.com

Campbell, C. (2018). the-last-of-us-ps4-play-e3-2018-sony. Retrieved from The Last of Us is worth returning to, 5 years later: www.polygon.com

Chandler, D. (2007). Semiotics : The Basic. London: Routledge.

Davidson, J. (2015). www.technobuffalo.com/fallout-4-steam-sales-24-hours. Retrieved from Techno Buffalo: www.technobuffalo.com

Horizon Zero Dawn. (2017). Retrieved from The Power of Teeth - Meet Mecha-Dinos Snapmaw \& Thunderjaw: www.mmorpg.com

Huizinga, J. (2014). Homo Ludens: A Study of the Play-Element in Culture. Martino Publishing.

Kirkpatrick, G. (2011). Aesthetic Theory and the Video game. Manchester: Manchester University Press.

Klappencbah, M. (2019). www.lifewire.com/top-Post-apocalyptic-video-games-813067. Retrieved from Lifewire: www.lifewire.com

Littlejohn, S. W. (2009). Theories of Human Communication. Jakarta: Salemba Humanika.

Newton, C. (2017). Why Horizon Zero Dawn is my game of the year. Retrieved from horizon-zero-dawn-game-of-the-year-2017: www.theverge.com

Ng, B. D., \& Wiemer-Hastings, P. (2005). Addiction to the Internet and Online Gaming. Cyberpsychology and Behaviour, 110-113.

Parfitt, B. (2017). www.mcvuk.com/news/read/horizon-zero-dawn-beats-zelda-to-no1/0179703. Retrieved from www.mcvuk.com

Piliang, Y. A. (2004). Posrealitas. Yogyakarta : Jalasutra.

Poole, S. (2017). Why video games are obsessed with the apocalypse. Retrieved from www.bbc.com

Ritzer, G. (2012). Teori Sosiologi. Yogyakarta: Pustaka Pelajar.

Salen, K., \& Zimmerman, E. (2004). Rules of Play. MIT Press.

Santoso, P. (2019). Retrieved from review-metro-exodus-arah-baru-mengagumkan: https://jagatplay.com

Sanyoto, S. E. (2010). Nirmana : Elemen-elemen Seni dan Desain. Yogyakarta: Jalasutra. Smuts, A. (2005). Are Video Games Art? Contemporary Aesthetic.

Straubhaar, J., \& LaRose, R. (2008). Media Now: Understanding Media, Culture, and Technology. Cengage Learning.

Tassi, P. (2013). Retrieved from Forbes: www.forbes.com 